\title{
Tratamientos estéticos. Posición de la Academia Nacional de Medicina de México
}

\author{
Armando Mansilla-Olivares, José Ignacio Santos-Preciado, Ricardo Plancarte-Sánchez, \\ Fernando Meneses-González, Fermín Valenzuela-Gómez-Gallardo, Joaquín López-Bárcena y \\ Gilberto Felipe Vázquez-De Anda \\ Academia Nacional de Medicina de México, Comité de Vinculación y Difusión del Conocimiento. Ciudad de México, México
}

\begin{abstract}
Resumen
En México existe una proliferación de "centros de medicina estética" que ofrecen tratamientos diversos con rayos láser, mesoterapia, ácido hialurónico e inyecciones con toxina botulínica por personal médico que no está capacitado ni certificado para asegurar la calidad de los servicios. La Academia Nacional de Medicina y el Comité Normativo Nacional de Consejos de Especialidades Médicas (CONACEM) comunican su postura al respecto.
\end{abstract}

PALABRAS CLAVE: Medicina estética. Masoterapia. Tratamiento con láser. Ácido hialurónico. Toxina botulínica.

\begin{abstract}
In Mexico there is a proliferation of "centers for aesthetic medicine" that offer different treatments with laser beam, mesotherapy and hyaluronic acid and botulinum toxin injections. In numerous centers of this type, offered and performed by medical personnel that are neither trained or certified to ensure the quality of services. The National Academy of Medicine of Mexico and the National Normative Council for Medical Specialties (CONACEM) communicate their posture on this matter.
\end{abstract}

KEY WORDS: Aesthetic medicine. Mesotherapy. Laser beam treatment. Hyaluronic acid. Botulinum toxin.

El interés personal por mantener o mejorar la apariencia estética ha promovido que la oferta especializada de la prestación de servicios médicos de cirugía plástica, estética y reconstructiva vaya en aumento a tal grado que actualmente "centros estéticos" sin el respaldo de un especialista certificado en el área, ofrecen tratamientos médicos con láser (manchas, varices, tatuajes), aplicación de mesoterapia, de ácido hialurónico o de toxina botulínica, sin la garantía médica ni la certeza jurídica que respalden la calidad de la intervención o de los tratamientos utilizados. Estos centros, en los que se comercializan tratamientos de medicina estética no aprobados científicamente y que realizan prácticas publicitarias engañosas, son dirigidos habitualmente por médicos generales que ostentan títulos de cursos no aprobados de medicina estética o de Maestría en Cirugía Estética que carecen del respaldo y del reconocimiento de instituciones como la Academia Nacional de Medicina de México, Academia Nacional de Cirugía del Comité Normativo Nacional de Consejos de Especialidades Médicas (CONACEM), que otorgan la idoneidad y con ello la certeza de la capacitación del profesional del especialista, para ejercer su conocimiento en su práctica profesional cotidiana.

Paralelamente han aparecido también una serie de cursos en distintos estados de la República que ofrecen maestrías o diversas especialidades en estética que, como se señalaba, no cuentan con la certificación correspondiente y cuyos egresados carecen, por ende, del conocimiento médico, de las destrezas quirúrgicas $y$ de las aptitudes necesarias para ofrecer al paciente
Fecha de recepción: 12-10-2018

Fecha de aceptación: 23-10-2018

DOI: 10.24875/GMM.18004745
Gac Med Mex. 2018;154:740-741

Disponible en PubMed www.gacetamedicademexico.com 
y a sus familiares la seguridad científica y calidad del conocimiento que se ejerce sobre el paciente. Por ello, estos cursos no deben permanecer ajenos al Programa Único de Especialidades Médicas (PUEM), al que se sujetan todas las instituciones de enseñanza superior en el país reconocidas oficialmente para otorgar un diploma de especialista, de maestría o doctorado, de acuerdo con el artículo 81, párrafos primero y segundo de la Ley General de Salud.

No obstante lo anterior, existen algunos centros educativos, en particular en el estado de Veracruz, que imparten planes y programas de estudio con reconocimiento oficial por parte de la Secretaría de Educación de dicho estado y que conforme a su reconocimiento de validez oficial de estudios uno de estos centros en especial está autorizado a ofrecer los grados académicos de especialidad o maestría en estética. Sin embargo, independientemente de lo anterior, los cursos no son de tiempo completo y se toman presencialmente los sábados y en línea, los días hábiles. De tal forma que si bien el grado de maestría les permite actividades de investigación o de docencia, no los autoriza a ejercer como especialistas en la práctica clínica y mucho menos en la quirúrgica. Por este motivo, el 18 de enero de 2017 el Consejo Nacional de Especialidades Médicas A. C. negó la autorización para que los egresados de ese centro presentaran el examen de certificación en el Consejo Mexicano de Cirugía Plástica, Estética y Reconstructiva, A.C.

Existe una asociación civil cuya denominación es Consejo Mexicano de Certificación en Medicina Estética, la cual no tiene reconocimiento ante el Conacem, por lo que carece de facultades de acreditación de terceros, independientemente del documento que aparentemente otorgó el notario público 211 del Distrito Federal en el libro 1,507, escritura 62,054, el 29 de enero de 2013. Esta asociación fue constituida, al igual que la Sociedad Mexicana de Medicina Estética, Nutrición, Antienvejecimiento y Homotoxicología, A. C., por la misma persona que al parecer dirige el Instituto de Estudios Superiores en Medicina, S. C. Por lo anterior, este consejo es totalmente ajeno al Conacem, a la
Academia Nacional de Medicina de México y a la Academia Mexicana de Cirugía.

Dada la importancia que tiene para la salud pública y el avance científico en nuestro país y ante la aparición de este tipo de asociaciones fuera del marco regulatorio, la Academia Nacional de Medicina de México, como órgano consultivo del gobierno federal y con el poder que le otorga la presidencia tripartita del Consejo Nacional de Academias, establece los siguientes considerandos:

- En la ciencia médica no existe la cirugía estética, ya que los tratamientos estéticos no son invasivos, por lo que no se requiere un procedimiento quirúrgico para su aplicación; de hecho, los procedimientos estéticos se basan en productos de naturaleza cosmética.

- En el contexto de la cirugía plástica o de la cirugía reconstructiva quedan subsumidos los procedimientos estéticos, pero no pueden desligarse si el tratamiento es invasivo, por ello la especialidad se denomina Cirugía Plástica, Estética y Reconstructiva. En consecuencia, la cirugía estética solo se da cuando es accesoria de una cirugía plástica o reconstructiva.

- Con base en todo lo anterior, la Academia Nacional de Medicina de México, en consonancia con la postura del Conacem, organismo auxiliar de la administración pública federal, informa que el Consejo Mexicano de Certificación en Medicina Estética, A.C. no cumple con el artículo 81, tercer párrafo, de la Ley General de Salud, y alerta a la comunidad médica y a la sociedad en general, sobre el engaño a la población de este tipo de asociaciones, que frustran las expectativas de los jóvenes e incurren en la inobservancia de la ley, provocando diversos tipos de iatrogenia y lesiones que ponen en peligro la vida de quienes se someten a este tipo de tratamiento, al depositar su confianza en personal no certificado en cuanto a sus conocimientos y habilidades. 